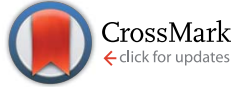

Cite this: Chem. Sci., 2016, 7, 5332

\title{
Elucidation of the heme active site electronic structure affecting the unprecedented nitrite dismutase activity of the ferriheme $b$ proteins, the nitrophorins $\uparrow$
}

\begin{abstract}
Chunmao He, * Hideaki Ogata and Wolfgang Lubitz*
Nitrophorins (NPs) catalyze the nitrite dismutation reaction that is unprecedented in ferriheme proteins. Despite progress in studying the reaction mechanism, fundamental issues regarding the correlation of the structural features with the nitrite dismutase activity of NPs remain elusive. On the other hand, it has been shown that the nitrite complexes of NPs are unique among those of the ferriheme proteins since some of their electron paramagnetic resonance (EPR) spectra show significant highly anisotropic low spin (HALS) signals with large $g_{\max }$ values over 3.2. The origin of HALS signals in ferriheme proteins or models is not well understood, especially in cases where axial ligands other than histidine are present. In this study several mutations were introduced in NP4. The related nitrite coordination and dismutation reaction were investigated. As a result, the EPR spectra of the NP-nitrite complexes were found to be tightly correlated with the extent of heme ruffling and protonation state of the proximal His liganddictated by an extended $\mathrm{H}$-bonding network at the heme active site. Furthermore, it is established that the two factors are essential in determining the nitrite dismutase activity of NPs. These results may provide a valuable guide for identifying or designing novel heme proteins with similar activity.
\end{abstract}

Received 4th March 2016

Accepted 23rd April 2016

DOI: $10.1039 /$ c6sc01019a

www.rsc.org/chemicalscience

\section{Introduction}

Nitrite is a major player in the nitrogen biogeochemical cycle, the biological fate of which is largely determined by a number of metalloproteins. ${ }^{1}$ Heme proteins are among the most important regulators of nitrite, catalyzing a variety of reactions-dictated by the heme core, ${ }^{1,2}$ e.g. the cytochrome $c$ nitrite reductase $(c c \mathrm{NiR}),{ }^{3}$ the assimilatory $\mathrm{NiR}(\mathrm{aNiR}),{ }^{4}$ and the two-domain protein cytochrome $c d_{1} \mathrm{NiR}^{5}{ }^{5}$ Recently, nitrite has been suggested as a viable source of nitric oxide (NO) in humans, thereby, it is involved in the signaling pathways. ${ }^{6}$ The reduction of nitrite to NO is facilitated by a number of human heme $b$ proteins, including hemoglobin $(\mathrm{Hb})$ and myoglobin $(\mathrm{Mb}) .^{7,8}$ It is worth noting that, although the detailed reaction mechanism remains elusive, ${ }^{7,9,10}$ all the functional heme proteins react at a ferrous oxidation state in the reduction of nitrite to NO.

Another heme $b$ containing protein class with a novel type of nitrite reaction is the nitrophorins (NPs) that originate from the saliva of the blood feeding insect Rhodnius prolixus. ${ }^{11,12}$ At least five isoforms appear concurrently in the insect saliva, termed NP1-4 and NP7. ${ }^{13,14}$ The biological function of the ferriheme

Max Planck Institute for Chemical Energy Conversion, Stiftstrasse 34-36, D-45470, Mülheim an der Ruhr, Germany.E-mail:chunmao82@gmail.com; wolfgang.lubitz@ cec.mpg.de

$\dagger$ Electronic supplementary information (ESI) available: Figures and tables. See DOI: $10.1039 / \mathrm{c} 6 \mathrm{sc} 01019 \mathrm{a}$ $b$ NPs has been established as an NO transporter. Interestingly, NPs were found to be able to convert nitrite into NO via a 'nitrite-only' mechanism with the stoichiometry of the nitrite disproportionation reaction. ${ }^{15}$

$$
3 \mathrm{NO}_{2}{ }^{-}+2 \mathrm{H}^{+} \rightarrow 2 \mathrm{NO}+\mathrm{NO}_{3}{ }^{-}+\mathrm{H}_{2} \mathrm{O}
$$

The ability of NPs to catalyze this reaction at neutral $\mathrm{pH}-$ that leads to the electron paramagnetic resonance (EPR)-silent $\{\mathrm{FeNO}\}^{6}$ complex according to the notation of Enemark and Feltham ${ }^{16}$-is unprecedented among any other hemes. The NPs are therefore classified as nitrite dismutases (EC 1.7.6.1). ${ }^{17}$

The coordination chemistry of heme iron with nitrite is important for understanding the catalytic mechanism of the enabling heme proteins. Several crystal structures of ferriheme proteins in complex with $\mathrm{NO}_{2}{ }^{-}$were solved and the related heme cores are summarized in Scheme 1. Similar to the model hemes, ${ }^{18,19}$ all structures of the NiR complexes show $\eta^{1}-\mathrm{N}$ (nitro) coordination. ${ }^{4,5,20-22}$ In all the cases of NiR, the ligand is further bound through H-bonding to Arg, His, or Lys side-chains. With the advent of the metHb[ $\left[\mathrm{NO}_{2}{ }^{-}\right]^{23}$ and metMb $\left[\mathrm{NO}_{2}{ }^{-}\right]$structures, ${ }^{24}$ the first examples of stable $\eta^{1}$-O coordinate heme nitrito complexes were reported (Scheme 1). Similarly, the nitrite was held by $\mathrm{H}$-bonding of $\mathrm{Fe}-\mathrm{O}_{\text {nitrite }}$ with the distal His and it was found that the distal H-bonding residues determine the $\mathrm{NO}_{2}{ }^{-}$ coordination mode. ${ }^{25}$ Like the globins, the heme $b$ protein 


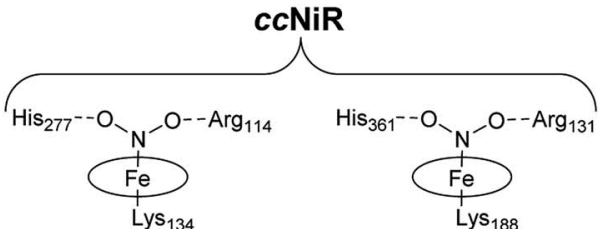

from $T$. nitratireductans from $W$. succinogenes PDB code: $2 \mathrm{E} 80$

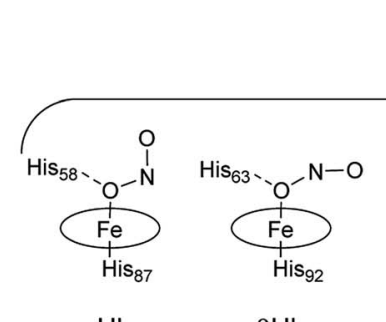

$\alpha \mathrm{Hb}$
PDB code:
3D1I

globins

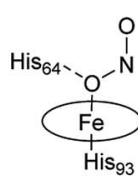

$\mathrm{Mb}$
2FRF

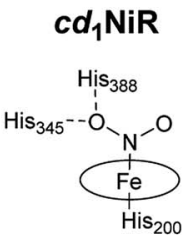

from $T$. panthotropia $1 \mathrm{AOQ}$
aNiR

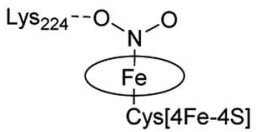

from tobacco

3VMO
SiRHP

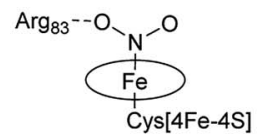

from E. coli

$3 G E O$

Scheme 1 Comparison of the nitrite binding modes in selected ferriheme protein complexes. (SiRHP, sulfite reductase hemoprotein).

chlorite dismutase (Cld) $-\mathrm{NO}_{2}{ }^{-}$has an $\eta^{1}$-O nitrite ligand that is further bound to Arg183. ${ }^{26}$ It is generally believed that the bound $\mathrm{NO}_{2}{ }^{-}$is activated through $\mathrm{H}$-bonding to the charged residues at the active site during turnover. ${ }^{1}$

In contrast to all reported crystal structures, the $\mathrm{NO}_{2}{ }^{-}$ligand in $\mathrm{NP} 4\left[\mathrm{NO}_{2}{ }^{-}\right]$is not H-bonded to any residue side-chain while the protein forms a classical N-bound nitro complex (Scheme 1). ${ }^{27}$ In probing the determining factors of the $\mathrm{NO}_{2}{ }^{-}$binding mode in NP4, the heme distal pocket variant NP4(L130R) was produced, the structure of which is almost the same as that of the wild-type (wt). ${ }^{28}$ Interestingly, $\mathrm{NO}_{2}{ }^{-}$remains $\mathrm{N}$-bound in this variant, demonstrating that, unlike the metMb[$\left[\mathrm{NO}_{2}{ }^{-}\right],{ }^{25}$ the presence of an $\mathrm{H}$-bond donating residue is not sufficient to change the mode of $\mathrm{NO}_{2}{ }^{-}$coordination in NP4. ${ }^{29}$ Thus, the question remains-how are the nitrite ligand orientation and the nitrite reductase activity determined in NPs?

EPR spectroscopy has been widely applied in probing the electronic configuration of the ferriheme- $\mathrm{NO}_{2}{ }^{-}$complexes. ${ }^{30} \mathrm{In}$ most of these complexes, two sets of $g$-values were obtained in Xband EPR spectra that reflect low-spin (LS) electron configurations $(S=1 / 2) .{ }^{27}$ In the cases of metMb $\left[\mathrm{NO}_{2}{ }^{-}\right]$and metHb $\left[\mathrm{NO}_{2}{ }^{-}\right]$, several suggestions were made related to the origin of the two species, for instance the concomitant appearance of O-bound and $\mathrm{N}$-bound nitrite ligands in frozen solutions in contrast to crystallographically ordered protein molecules where only the $\mathrm{O}$ bound nitrito mode could be resolved. ${ }^{31,32}$ However, the exact reason for the origin of the two components in EPR spectra is currently not clear. Of all the ferriheme- $\mathrm{NO}_{2}{ }^{-}$complexes found in the literature, $\mathrm{NP} 4\left[\mathrm{NO}_{2}{ }^{-}\right]$represents the most extreme case in the sense that besides the "normal" rhombic signal with $g=$ $(2.74,2.42,1.51)$, a spectrum with a "large $g_{\max }$ " type of signal at $g_{\max }=3.38$ was also resolved (Fig. 1)..$^{27}$

The EPR spectrum directly reflects the electron configuration of LS $\mathrm{d}^{5}$ porphyrinates. There are two limiting electron configurations for such a system that give rise to three types of EPR spectra: (a) the normally observed $\left(\mathrm{d}_{x y}\right)^{2}\left(\mathrm{~d}_{x z}, \mathrm{~d}_{y z}\right)^{3}$ configuration, for which the EPR spectra may be either "large $g_{\max }$ " (type I, usually with only a single observable $g$ value $>3.2$, the so-called highly anisotropic low-spin (HALS) EPR signal) or normal rhombic (type II, with three observable $g$-values) in appearance; (b) the $\left(\mathrm{d}_{x z}, \mathrm{~d}_{y z}\right)^{4}\left(\mathrm{~d}_{x y}\right)^{1}$ configuration, for which an "axial" type of the EPR spectrum is observed (type III, $2.6 \geq g_{\perp}>2>g_{\|}$). ${ }^{33} \mathrm{In}$

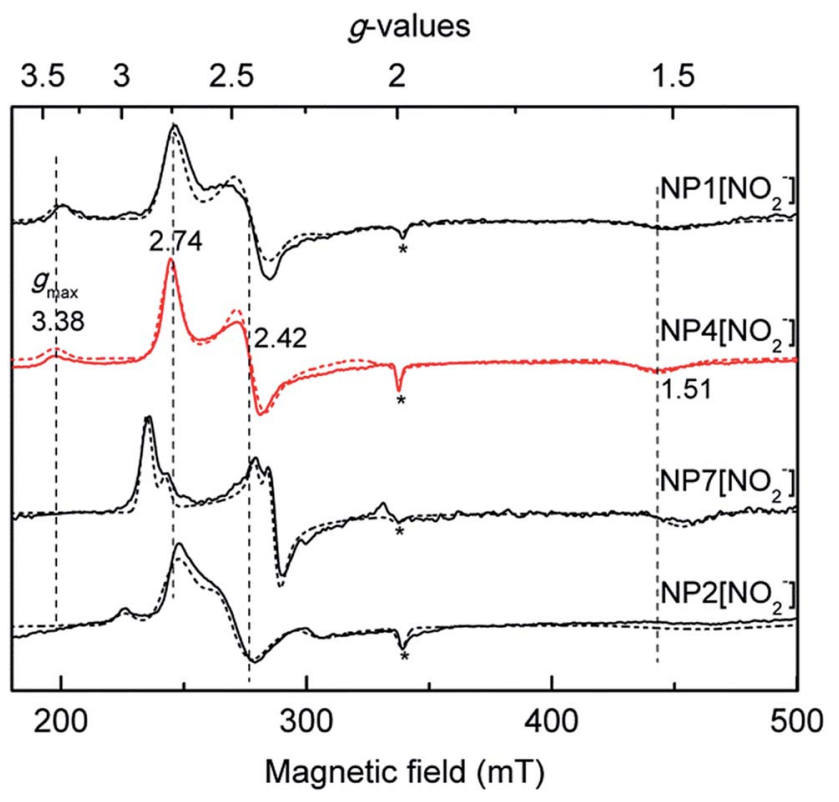

Fig. 1 Comparison of the X-band EPR spectra of the nitrite complexes of different NPs recorded at $10 \mathrm{~K}$, with the simulated spectra shown in dashed lines (see Fig. $\mathrm{S} 2 \uparrow$ for $g$-values used for the simulations). For comparison, the positions of the $g$-values of NP4 are indicated with dashed vertical lines. Note that in all the cases a small fraction of the high-spin signal was observed (*), possibly due to a water-bound ferriheme complex. 
type I hemes the energy difference between the $d_{x z}$ and $d_{y z}$ orbitals may be so small that they become near-degenerate and this leads to the tetragonal distortion of the d orbitals, showing a HALS EPR signal; as the energy gap between the two orbitals increases, the degeneracy is removed and a rhombic distortion is observed (type II). In a quite distinct ground state (type III), the $\mathrm{d}_{x z}, \mathrm{~d}_{y z}$ orbitals are nearly degenerate and below the $\mathrm{d}_{x y}$ orbital in energy (see Fig. S1† for the splitting pattern of the LS $\mathrm{d}^{5}$ orbitals). In bis-His coordinated ferriheme systems the HALS species is related to the perpendicularly oriented His planes with respect to each other, whereas the rhombic signal is related to a more parallel orientation. ${ }^{33-36}$ However, as far as two different heme ligands-like in the case of cytochrome $c$ (His and Met) ${ }^{37,38}$ - are concerned, there is no clear cut difference between the large $g_{\max }$ and "normal" rhombic cases as a result of the relative ligand orientation. Rather, other factors have been suggested to modulate the electronic structures of the ferriheme center, such as heme ruffling and the bonding strength of the axial ligand. ${ }^{37-41}$ Therefore, it is not clear whether the HALS and rhombic signals observed in $\mathrm{NP} 4\left[\mathrm{NO}_{2}{ }^{-}\right]$are related to different $\mathrm{NO}_{2}{ }^{-}$orientations with respect to the proximal His residue or if there are other contributing factors. A more detailed study is required to understand the molecular structural basis of the unique EPR spectrum observed in this case.

Herein, we report the first combined EPR spectroscopic and structural investigation on the nitrite complexes with various NP isoforms and NP4 variants. The outcome of the study promises to be highly relevant for elucidating the key factors contributing to the unprecedented nitrite dismutase activity of the nitrophorins.

\section{Results and discussions}

\section{The influence of heme ruffling in different NPs}

The heme out-of-plane distortion, e.g. ruffling, was reported to be able to affect the ground electronic configuration (and hence the line shape of the EPR spectrum) of the related LS $\mathrm{d}^{5}$ complex. $^{39-41}$ It is well-known that NPs have highly ruffled hemes, and therefore, possible correlations between the observed HALS EPR signal of $\mathrm{NP} 4\left[\mathrm{NO}_{2}{ }^{-}\right]$and heme ruffling were probed. The EPR spectrum of the isoform, $\mathrm{NP} 7\left[\mathrm{NO}_{2}{ }^{-}\right]$, showed no HALS signal (Fig. 1); rather, two sets of rhombic signals were resolved (LS1, $g=2.86,2.34,1.46 ; \mathrm{LS} 2, g=2.78,2.40,1.46) .{ }^{27}$ Herein, we measured the EPR spectra of the nitrite complexes with other NPs, e.g. NP1 and NP2. The relative contribution of the two types of signals, i.e. HALS and rhombic LS, was estimated from the simulated spectra. All EPR simulation files are provided in the ESI (Fig. S2 $\dagger$ ). In all the cases, a small fraction of the high-spin signal at $g \cong(6.0,6.0,2.0)$ was observed, which is probably due to a water coordination complex. For $\mathrm{NP} 4\left[\mathrm{NO}_{2}{ }^{-}\right]$, a HALS signal is clearly observed $(\approx 30 \%)$. It can be seen that $\mathrm{NP} 1\left[\mathrm{NO}_{2}{ }^{-}\right]$also has a HALS signal with a similar ratio as in the case of $\mathrm{NP} 4\left[\mathrm{NO}_{2}{ }^{-}\right]$, whereas $\mathrm{NP} 2\left[\mathrm{NO}_{2}{ }^{-}\right]$shows only two rhombic species with LS1, $g=(2.95,2.23,1.41)$ and LS2, $g=(2.70,2.48$, 1.44) (Fig. 1 and Table 1).
The degree of heme ruffling of the NP complexes was derived from the root-mean-square deviations (RMSD) from the heme mean plane as reported. ${ }^{11}$ An analysis of the heme ruffling of NPs reveals a seemingly clear trend of increasing ruffling with decreasing HALS species (Table 1). While there are relatively large differences in the degree of heme ruffling among different NPs $(\mathrm{RMSD}=0.25 \AA$ for NP2 vs. $\mathrm{RMSD}=0.15 \AA$ for NP4), it is not the case among the variants of a specific isoform, e.g. NP4. As we shall see later, the NP4 variants-although with similar heme ruffling situations-have very different EPR spectra for their nitrite complexes. Therefore, other factors may also contribute significantly to the origin of the HALS EPR signal in the nitrite complexes of NPs.

\section{The influence of the protonation state of the proximal His ligand in NP4 variants}

It is widely accepted that the axial ligand can have a strong impact on the electronic structure of the heme iron center. ${ }^{\mathbf{4 3}}$ Notably, as a common axial ligand the histidine side-chain can adopt multiple protonation states, i.e. neutral, $\mathrm{N}^{\varepsilon}$ protonated (histidinum), and $\mathrm{N}^{\delta}-\mathrm{H}$ deprotonated (histidinate) (see Fig. S3† for details). The proximal heme ligand of NP2, i.e. His57, has a slight histidinate character (partially deprotonated) due to the weak H-bond network involving a water molecule, the Asn68 residue, and the $\mathrm{P} 6$ heme propionate (Scheme $2 \mathrm{~A}) .^{\mathbf{4 4}}$ Interestingly, the Asn residue in NP2 is replaced by an Asp residue at the corresponding position in wt NP4 (Scheme 2B), where the bridging water molecule is conserved. Amino acid sequence alignment of NPs is provided in Fig. $\mathrm{S} 4, \dagger$ from which we can see that either an Asp or Asn is present at this position. Even more strikingly, the Asp70 residue in NP4 is part of an extended $\mathrm{H}$-bonding network which involves the two heme propionates and the Lys125 residue. In this case, the ability to abstract the proton of the $\mathrm{N}^{\delta} \mathrm{H}$ group of the axial His59 is much higher and it may lead to a more pronounced histidinate character of the His59 in NP4. In order to probe the possible consequences of the strengthened histidinate character on the electronic structure of the nitrite complex, a series of mutations have been introduced and the EPR spectra of the corresponding nitrite complexes recorded. Mutation of Asp70 to Asn in NP4-to mimic the NP2 environment-leads to a much lower ratio of the HALS species in the EPR spectrum of its nitrite complex, $\approx 16 \%$ (Fig. 2 and Table $\mathrm{S} 1 \dagger$ ). The presence of a HALS signal in this case suggests the contribution of the two heme propionates, which are now mediated by the newly introduced Asn residue (Scheme $2 \mathrm{~B}$ ). It is proposed that the negatively charged heme propionate would abstract the proton of the $\mathrm{N}^{\delta} \mathrm{H}$ group of the axial His59 through the extended H-bonding network (Scheme 2B). A further mutation of Asp70 to either Ala or Val completely suppresses the HALS signal in the nitrite complex, i.e. only rhombic EPR signals can be observed (Fig. 2 and Table S1†). In both cases, the two heme propionates are decoupled from the rest of the $\mathrm{H}$-bonding network and the His59 residue is essentially neutral, i.e. with the $\mathrm{N}^{\delta} \mathrm{H}$ proton (Scheme 2C). It can be seen that these NP4 variants, although similar in heme ruffling deformation, exhibit a very different ratio of HALS signals in 
Table 1 Collection of the low-spin $g$-values of the nitrite complexes of NPs and related heme distortion

\begin{tabular}{|c|c|c|c|c|c|c|c|c|c|}
\hline \multirow[b]{2}{*}{ Protein complex } & \multicolumn{3}{|c|}{ HALS or LS1 } & \multicolumn{3}{|l|}{ LS2 } & \multirow[b]{2}{*}{ Relative spin contribution of HALS ${ }^{b}$} & \multicolumn{2}{|c|}{$\begin{array}{l}\text { Heme distortion in } \mathrm{NP}\left[\mathrm{NH}_{3}\right] \\
\text { complexes }\end{array}$} \\
\hline & $g_{1}$ & $g_{2}$ & $g_{3}$ & $g_{1}$ & $g_{2}$ & $g_{3}$ & & $\operatorname{RMSD}^{d}(0.01 \AA)$ & PDB code \\
\hline $\mathrm{NP} 4\left[\mathrm{NO}_{2}^{-}\right]^{c}$ & 3.38 & $-^{a}$ & $-^{a}$ & 2.74 & 2.42 & 1.51 & $\approx 30 \%$ & 14.9 & $1 \mathrm{X} 8 \mathrm{P}$ \\
\hline $\mathrm{NP} 1\left[\mathrm{NO}_{2}^{-}\right]$ & 3.33 & $-^{a}$ & $-^{a}$ & 2.72 & 2.41 & 1.50 & $\approx 30 \%$ & 13.9 & $2 \mathrm{NP1}$ \\
\hline $\mathrm{NP} 2\left[\mathrm{NO}_{2}^{-}\right]$ & 2.95 & 2.23 & 1.41 & 2.70 & 2.48 & 1.44 & $\approx 0 \%$ & 24.9 & $1 \mathrm{EUO}$ \\
\hline
\end{tabular}

$a$ "Large $g_{\text {max }}$ type of spectrum, $g_{2}$ and $g_{3}$ are not observable. ${ }^{b}$ Data obtained from spectra simulations. ${ }^{c}$ From ref. $27 .{ }^{d}$ Calculated based on the heme core using the program Olex $2 .^{42}$

their nitrite complexes (Table S1 $\dagger$ ). The histidinate character of the axial His ligand is thus concluded to be an important factor for the appearance of HALS signals in the nitrite complexes of NPs.

Besides the proximal His ligand, the H-bond interactions between the axial ligand and the distal heme pocket residues may also have a significant impact on the electronic structure and reactivity of the heme complexes. The most well-known examples are the peroxidases where a distal His residue and the related $\mathrm{H}$-bonds are essential for the polarization/cleavage of the $\mathrm{O}-\mathrm{O}$ bond as they provide a "pull" effect on the distal side (Fig. 3B). ${ }^{4-50}$ Such an effect of the positively charged His52 in cytochrome $c$ peroxidase ( $\mathrm{CcP}$ ) was proposed, by density functional calculations, to be mediated by a bridging water molecule. ${ }^{50,51}$ As mentioned in the introduction (see Scheme 1), unlike other protein-nitrite complexes, there is no amino acid residue in the distal heme pocket of the $\mathrm{NP} 4\left[\mathrm{NO}_{2}{ }^{-}\right]$complex which could form an $\mathrm{H}$-bond directly to the nitrite ligand. However, two water molecules are present and are involved in an H-bonding network that connects the Asp30 residue to the nitrite ligand (compare Fig. 3A). Note that the Asp residue is highly conserved in the NP family (Fig. S4†). In a previous study, we showed that the NP4(D30N) variant has almost no nitrite dismutase activity, thus concluding that Asp30 is a key residue for its activity. ${ }^{29}$ Inspired by this result, we measured the EPR spectrum of the nitrite complex with NP4(D30N) (Fig. 2).

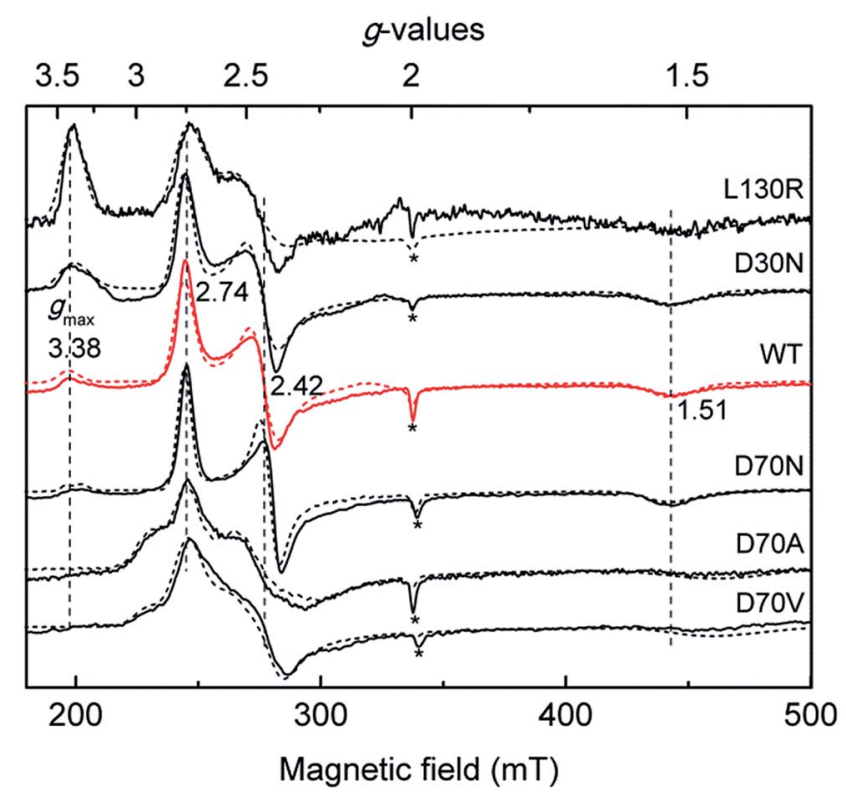

Fig. 2 Comparison of the X-band EPR spectra of the nitrite complexes of NP4 variants recorded at $10 \mathrm{~K}$, with the simulated spectra shown in dashed lines (see Fig. $\mathrm{S} 2 \uparrow$ for $g$-values used for the simulations). For comparison, the positions of the $g$-values of wt $\mathrm{NP} 4\left[\mathrm{NO}_{2}{ }^{-}\right]$are indicated with dashed vertical lines. Note that in all the cases a small fraction of the high-spin signal was observed (*), possibly due to a water-bound ferriheme complex.
(A)

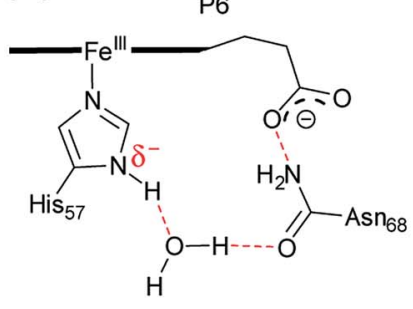

NP2
(B)

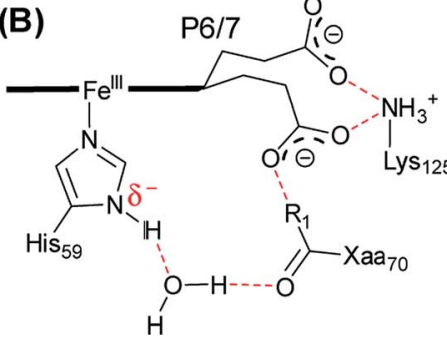

$\mathrm{NP4}(\mathrm{wt}): \mathrm{R}_{1}=-\mathrm{OH} ; \mathrm{Xaa}=$ Asp $\mathrm{NP} 4(\mathrm{D} 70 \mathrm{~N}): \mathrm{R}_{1}=-\mathrm{NH}_{2} ; \mathrm{Xaa}=\mathrm{Asn}$
(C)

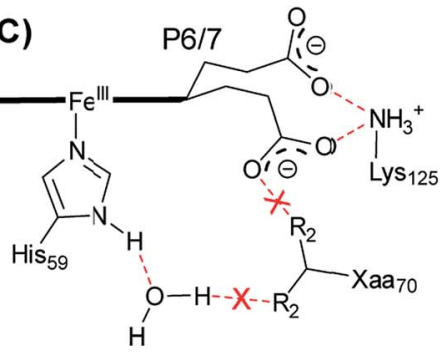

NP4(D70A): $\mathrm{R}_{2}=-\mathrm{H} ; \mathrm{Xaa}=\mathrm{Ala}$ $\mathrm{NP4}(\mathrm{D} 70 \mathrm{~V}): \mathrm{R}_{2}=-\mathrm{CH}_{3} ; \mathrm{Xaa}=\mathrm{Val}$

Scheme 2 Schematic representation of the $\mathrm{H}$-bonding network of the heme active site in the cases of NP2 ((A), PDB code 1EUO), NP4 and its variants ((B) and $(C)$, derived from PDB code 1 X8P). Note: this scheme is drawn on the basis of the X-ray structures and the $\mathrm{H}$-bonds are indicated in red. The protonation state provided here is only tentative. The heme macrocycle is presented as a bold line. The heme propionates are indicated as P6, P7. 


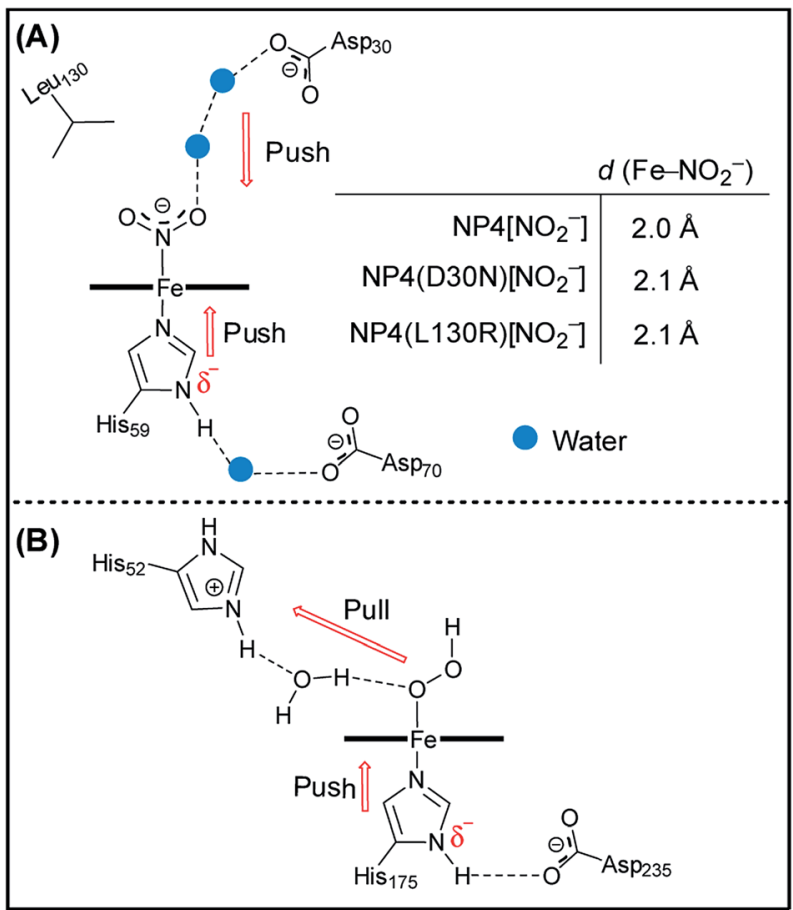

Fig. 3 The active site (heme) environment of $\mathrm{NP} 4\left[\mathrm{NO}_{2}{ }^{-}\right]((\mathrm{A}), \mathrm{PDB}$ code: $3 \mathrm{MVF}$ ) and a CcP with the modeled $\mathrm{H}_{2} \mathrm{O}_{2}$ substrate (compound 0 ) highlighting the push-pull mechanism ((B), adapted from ref. 50 and 51). The protonation state provided here is tentative, and for representation purposes.

Interestingly, it shows a significantly increased ratio of HALS species $(\approx 60 \%)$ compared to that of the wt NP4[ $\left[\mathrm{NO}_{2}{ }^{-}\right]$(Table $\mathrm{S} 1 \dagger)$. An even more pronounced HALS signal has previously been observed for another distal heme pocket variant$\mathrm{NP} 4(\mathrm{~L} 130 \mathrm{R})\left[\mathrm{NO}_{2}{ }^{-}\right]$, namely $\approx 72 \% .^{29}$

In a next step, we crystallized the NP4(D30N) $\left[\mathrm{NO}_{2}{ }^{-}\right]$complex and solved its structure (PDB code: 5HWZ, Fig. S5 $\dagger$ ). It shows that nitrite binds to the heme iron in an N-bound nitro form like in the cases of $\mathrm{NP} 4\left[\mathrm{NO}_{2}{ }^{-}\right]$and NP4(L130R) $\left[\mathrm{NO}_{2}{ }^{-}\right]$(Scheme 1). The two mutations $\mathrm{D} 30 \mathrm{~N}$ and L130R, however, dramatically interfere with the distal heme pocket in the sense that the Asp $30 \cdots$ water $\cdots$ water $\cdots$ nitrite $\mathrm{H}$-bonding network of the wt protein is disrupted in both cases (Fig. S6 $†$ ). The increase of HALS species in the nitrite complexes of the two variants therefore suggests the contribution of the negatively charged Asp30. In contrast to the positively charged His52 residue in $\mathrm{CcP}$, Asp30 in NP4 may exert a slight electron-donating ("push") effect on the bound nitrite ligand. Such a "push" effect may weaken the "push" effect from the proximal histidinate residue (compare Fig. 3A). Consequently, removing the distal "push" effect-through either replacement by a neutral residue as is the case of the D30N mutation (Fig. S6C $\dagger$ ) or introduction of a positively charged residue as is the case of the L130R mutation (Fig. S6B $\uparrow$ )-may indirectly strengthen the "push" effect of the proximal histidinate residue. In doing so, NP4(D30N) $\left[\mathrm{NO}_{2}{ }^{-}\right]$ and $\mathrm{NP} 4(\mathrm{~L} 130 \mathrm{R})\left[\mathrm{NO}_{2}{ }^{-}\right]$show clearly increased HALS species compared to that of the wt protein. In line with this is the EPR spectrum of $\mathrm{NP} 4\left[\mathrm{NO}_{2}{ }^{-}\right]$measured at $\mathrm{pH} 10.5$ where a more pronounced HALS signal is observed $(\approx 50 \%$, Fig. S2J and Table $\mathrm{S} 1 \dagger)$, here it is expected that the proximal His residue will deprotonate to a greater extent at a higher $\mathrm{pH}$ value. As such, it unambiguously assigns the histidinate character of the proximal His residue as a cause of the HALS EPR signal in NP4 $\left[\mathrm{NO}_{2}{ }^{-}\right]$.

\section{Implications for the nitrite dismutase activity}

Heme ruffling leads to overlap of the $\mathrm{p}_{\pi}$ orbitals of the heme nitrogens with the $\mathrm{d}_{x y}$ orbital of the metal, so that the electronic interaction between the porphyrin $\mathrm{a}_{2 \mathrm{u}}(\pi)$ orbital and the metal $\mathrm{d}_{x y}$ orbital is switched on, as described in model heme complexes. ${ }^{52}$ This way ruffling helps to stabilize the $\left(\mathrm{d}_{x z}, \mathrm{~d}_{y z}\right)^{4}\left(\mathrm{~d}_{x y}\right)^{1}$ ground state of the LS $\mathrm{d}^{5}$ ferrihemes, which has been reported for model ferriheme complexes ${ }^{53,54}$ and in the $\mathrm{CN}^{-}$complexes of NPs. ${ }^{55,56}$ Such an electronic configuration is proposed to be important for $\mathrm{NP}[\mathrm{NO}]$ complexes, in which the unpaired electron of the NO ligand would be located on the NO moiety. Due to orbital orthogonality, the NO unpaired electron and the $\mathrm{Fe}^{\mathrm{III}}\left(\mathrm{d}_{x y}\right)^{1}$ of NPs may be coupled magnetically, leading to an $\mathrm{Fe}^{\mathrm{III}}\left(\mathrm{d}_{x y}\right){ }^{-}$- NO configuration that is ready for NO release when needed. ${ }^{11}$ The EPR spectra of the nitrite complex of NPswith either type I or type II signals-clearly indicate the $\left(\mathrm{d}_{x y}\right)^{2}\left(\mathrm{~d}_{x z}, \mathrm{~d}_{y z}\right)^{3}$ configuration of the ferriheme centers, at cryogenic temperatures, e.g. $10 \mathrm{~K}$. However, the general trend of increasing ruffling with decreasing HALS species, i.e. smaller $g$-anisotropy, observed among the nitrite complexes with different NP isoforms seems to suggest a contribution of the $\left(\mathrm{d}_{x z}, \mathrm{~d}_{y z}\right)^{4}\left(\mathrm{~d}_{x y}\right)^{1}$ configuration. The most ruffled $\mathrm{NP} 2\left[\mathrm{NO}_{2}{ }^{-}\right]$, with no HALS signal, may have more of the $\left(\mathrm{d}_{x z}, \mathrm{~d}_{y z}\right)^{4}\left(\mathrm{~d}_{x y}\right)^{1}$ configuration, whereas the less ruffled $\mathrm{NP} 4\left[\mathrm{NO}_{2}{ }^{-}\right]$, with significantly more HALS signal, may adopt more of the $\left(\mathrm{d}_{x y}\right)^{2}\left(\mathrm{~d}_{x z}, \mathrm{~d}_{y z}\right)^{3}$ configuration. Adding to this is the fact that a $\left(\mathrm{d}_{x y}\right)^{2}\left(\mathrm{~d}_{x z}, \mathrm{~d}_{y z}\right)^{3}$ system may switch to a $\left(\mathrm{d}_{x z}, \mathrm{~d}_{y z}\right)^{4}\left(\mathrm{~d}_{x y}\right)^{1}$ system at elevated temperatures, as reported for model complexes ${ }^{57}$ and heme proteins. ${ }^{56,58}$ This supports the idea that strong ruffling of the

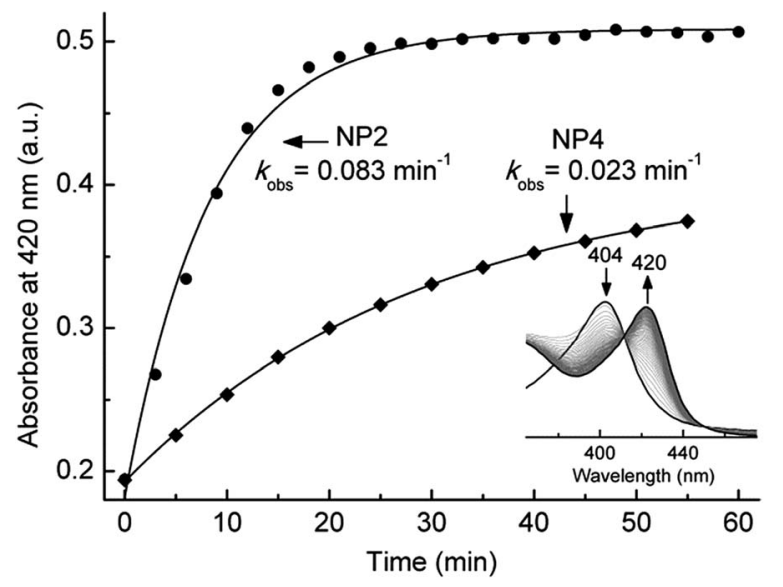

Fig. 4 UV-vis absorbance changes at $420 \mathrm{~nm}$-from which the $k_{\text {obs }}$ was calculated-for the reaction of nitrite $(20 \mathrm{mM})$ with NP2 $(\approx 5 \mu \mathrm{M})$ and NP4 $(\approx 5 \mu \mathrm{M})$ at $37^{\circ} \mathrm{C}$ in $0.1 \mathrm{M}$ phosphate buffer $(\mathrm{pH} 6.5)$. Insert: typical UV-vis absorption spectra for the reaction of NPs with nitrite. 
$\mathrm{NP}\left[\mathrm{NO}_{2}{ }^{-}\right]$complexes could stabilize a partial $\left(\mathrm{d}_{x z}, \mathrm{~d}_{y z}\right)^{4}\left(\mathrm{~d}_{x y}\right)^{1}$ ground electronic configuration, especially under physiological conditions, e.g. at $37^{\circ} \mathrm{C}$. It is worth noting that the coordination of $\mathrm{NO}_{2}^{-}$, a reasonably strong $\pi$-acceptor ligand, ${ }^{59}$ may also contribute to stabilizing a $\left(\mathrm{d}_{x z}, \mathrm{~d}_{y z}\right)^{4}\left(\mathrm{~d}_{x y}\right)^{1}$ configuration of the Fe centers in the $\mathrm{NP}\left[\mathrm{NO}_{2}{ }^{-}\right]$complexes. As mentioned, heme ruffling may help to stabilize the ferriheme $\mathrm{NP}[\mathrm{NO}]$ complexes through a $\left(\mathrm{d}_{x z}, \mathrm{~d}_{y z}\right)^{4}\left(\mathrm{~d}_{x y}\right)^{1}$ configuration. Since this is a final product for the nitrite dismutation reaction catalyzed by NPs (eqn (1)), we speculated that NPs with a more ruffled heme should have a higher activity due to a comparable electron configuration, i.e. $\left(\mathrm{d}_{x z}, \mathrm{~d}_{y z}\right)^{4}\left(\mathrm{~d}_{x y}\right)^{1}$. In light of this, the nitrite dismutase activity of NP2 and NP4 was measured and compared in Fig. 4. It clearly shows that NP2 reacts much faster with nitrite $\left(k_{\mathrm{obs}}=0.083 \mathrm{~min}^{-1}\right.$ vs. $k_{\mathrm{obs}}=0.023 \mathrm{~min}^{-1}$ for NP4 $)$. As discussed, the heme ruffling contributes to the decrease of $g$ anisotropy in the EPR spectra of the nitrite complexes of NPs, whereas the HALS signal observed is due to a more planar heme. As far as the functional consequence is concerned, it is the ruffled heme which facilitates the nitrite dismutation reaction. It is worth noting in this context, that heme ruffling is known to stabilize the $3+$ oxidation state of the iron center, i.e. lowers the heme $\mathrm{Fe}^{\mathrm{III}} / \mathrm{Fe}^{\mathrm{III}}$ redox potential, in a number of ferriheme proteins..$^{58,60-62}$ We have shown that a lower redox potential of the heme iron center is the key to NPs' nitrite dismutase activity. ${ }^{63}$ It can be rationalized that NPs, by adopting a ruffled heme conformation, have a much lower redox potential relative to other hemeproteins, e.g. metMb $(\approx 300 \mathrm{mV}$ more positive), ${ }^{11}$ which is essential for their unique reactivity with nitrite.

As described above, the significantly increased ratio of HALS species in the nitrite complexes of the two NP4 variants, namely NP4(D30N) and NP4(L130R), has been attributed to the presence of a partially deprotonated proximal His ligand, i.e. a histidinate. The nitrite dismutase activity in the two variants has been shown to have almost disappeared, ${ }^{29}$ apparently not because of heme ruffling changes (Table S1†). The importance of H-bonding to the proximal His residue in controlling heme protein activity has long being discovered, with the Asp-His-Fe triad of CcP being one of the most extensively studied systems. $^{45-50}$ Therefore, a possible role of the histidinate character of the proximal His residue in modulating the nitrite dismutase activity of NPs is suspected. Upon deprotonation, the resulting imidazolate moiety of the proximal His is expected to be a stronger field ligand than the neutral imidazole. ${ }^{46,64,65}$ The negative charge on the imidazolate, via increased ligand field strength, is generally central in modulating many of the reactivity and ligand-binding properties of heme proteins. In the cases of the nitrite complexes of NP4(L130R) and NP4(D30N), a negatively charged proximal histidinate-resulting from the perturbation of the $\mathrm{H}$-bonding network in the distal heme pocket-would lead to a weakened $\mathrm{Fe}-\mathrm{N}_{\text {nitrite }}$ coordination compared to that of the wt protein due to the trans effect or electron-electron (anion-anion) repulsion. In line with this are the slightly larger $\mathrm{Fe}-\mathrm{N}_{\text {nitrite }}$ bond distances observed in the complexes of NP4(L130R) $\left[\mathrm{NO}_{2}{ }^{-}\right](2.1 \AA)$ and NP4(D30N) $\left[\mathrm{NO}_{2}{ }^{-}\right]$ $\left(2.1 \AA\right.$ ) compared to that of $\mathrm{NP} 4\left[\mathrm{NO}_{2}^{-}\right]$(2.0 ̊) (compare Fig. 3).
As such, the weakly bound initial nitrite complexes could contribute to the much lower nitrite dismutase activity observed for the two variants. Moreover, it was demonstrated that the $\mathrm{Fe}$ center of a porphyrin[ $\left[\mathrm{Fe}^{\mathrm{III}}-\mathrm{NO}_{2}{ }^{-}\right]$complex is extremely electron deficient and to relieve the "hunger for electron density" is a major driving force for many of its reactivities. ${ }^{59}$ In this regard, a negatively charged proximal histidinate ligand is expected to push more electron density into the $\mathrm{Fe}$ center, e.g. of the $\mathrm{NP} 4(\mathrm{~L} 130 \mathrm{R})\left[\mathrm{NO}_{2}{ }^{-}\right]$and $\mathrm{NP} 4(\mathrm{D} 30 \mathrm{~N})\left[\mathrm{NO}_{2}{ }^{-}\right]$complexes, thereby, satisfying its electron demand to some extent. Consequently, the tendency to relieve the "hunger for electron density", i.e. to react, is diminished in these complexes, as observed in a previous study. ${ }^{29}$ On the contrary, in the cases of other NP4 variants where Asp70 is mutated to either Val or Ala and the proximal His residue is essentially neutral (compare Scheme 2C), the corresponding nitrite dismutase activity is higher compared to that of the wt NP4 (e.g. $k_{\text {obs }}=0.07 \mathrm{~min}^{-1}$ for NP4(D70A), Fig. S7 $\dagger$ ). As a result, it establishes that a histidinate character of the proximal His residue contributes significantly to the lowering of the nitrite dismutase activity of the NPs. It is well-known that the nitrite dismutation catalyzed by NPs is strongly pH-dependent, with a much smaller reaction rate at high $\mathrm{pH}$, e.g. $>7.5 .^{15}$ From the discussion above, it can be deduced that the smaller activity is due to a stronger histidinate character of the proximal His residue in this case.

\section{Conclusions}

The origin of the unprecedented HALS EPR signals of the NP $\left[\mathrm{NO}_{2}{ }^{-}\right]$complexes has been extensively investigated in this study. It is established that both heme conformation, e.g. ruffling, and the protonation state of the proximal His residue can affect the EPR spectra of the corresponding nitrite complexes. More importantly, both factors contribute to the nitrite dismutase activity of NPs. The highly ruffled hemes in $\mathrm{NPs}$, and the concomitantly decreased $\mathrm{Fe} \mathrm{eII}^{\mathrm{II}} / \mathrm{Fe}^{\mathrm{II}}$ redox potentials as compared to those in most other heme $b$ proteins or model complexes, place them in a unique position to facilitate nitrite dismutation. However, heme ruffling or low redox potential is not the only reason; otherwise other ferriheme $b$ proteins, e.g. the peroxidases which are known to have a low redox potential, ${ }^{66}$ may also catalyze the reaction. As discussed, the histidinate character of the proximal His residue, or more precisely the extended H-bonding network at the heme active site, also plays a pivotal role in determining the nitrite dismutase activity in NPs. In this regard, a neutral proximal His residue proves to be more reactive (discussed above), which is probably the major reason why such activity is not found in peroxidases-where hemes are also highly distorted ${ }^{67}$ and the $\mathrm{Fe}^{\mathrm{III}} / \mathrm{Fe}^{\mathrm{II}}$ redox potentials can be as low as those in NPs $(+5$ to $-310 \mathrm{mV}$ for peroxidases $^{66}$ vs. -259 to $-335 \mathrm{mV}$ for $\left.\mathrm{NPs}^{68,69}\right)$. Similarly, NP4(D30N) was reported to have a lower redox potential than that of the wt NP4 (-429 mV for NP4(D30N) vs. $-384 \mathrm{mV}$ for wt NP4 at pH 5.0), ${ }^{70}$ however, it cannot react with nitrite, which clearly argues for the role of the H-bonding network of NPs in determining the nitrite dismutase activity. 
In summary, the key factors that facilitate the nitrite dismutase reaction of NPs have been established to be the heme ruffling and an extended $\mathrm{H}$-bonding network at the active site which helps to keep the proximal His residue neutral. We believe the structural features revealed herein would be very helpful in identifying other heme proteins, especially in mammals, which may have similar activity. Moreover, it can serve as a guideline for the design of model heme complexes or heme proteins with (enhanced) nitrite dismutase activity.

\section{Experimental}

\section{Materials}

Stock solutions of $\mathrm{NaNO}_{2}$ were prepared freshly before use and the concentration was photometrically calibrated $\left(\varepsilon_{210} \mathrm{~nm}=\right.$ $\left.5380 \mathrm{M}^{-1} \mathrm{~cm}^{-1}\right) .{ }^{71}$ All other reagents were of the highest grade commercially available and used as received. Expression plasmids for the preparation of the protein variants NP4(D70 $\rightarrow \mathrm{A} / \mathrm{V} /$ $\mathrm{N})$ were commercially derived from the expression plasmid of $\mathrm{wt}$ NP4 (GenScript Inc.).

\section{Protein preparation}

NP4 and its variants NP4(D30N), NP4(D70V), NP4(D70A), NP4(D70N), and NP4(L130R) as well as the wt forms of NP1, NP2, and NP7 were recombinantly expressed in the Escherichia coli strain BL21(DE3) (Novagen) and purified and reconstituted as was previously described. ${ }^{\mathbf{1 3}, 72}$ Protein preparations were routinely analyzed by SDS-PAGE to be $>90 \%$ pure. The proteins were subjected to MALDI Q-TOF MS to confirm the correct molecular masses accounting for two Cys-Cys disulfides. Proteins were kept frozen in $200 \mathrm{mM} \mathrm{NaOAc/AcOH}$ (pH 5.5), 5\% $(\mathrm{w} / \mathrm{v})$ glycerol until use.

\section{EPR spectroscopy}

The solvent of the protein was exchanged to $100 \mathrm{mM}$ HEPES/ $\mathrm{NaOH}$ (pH 7.2), 25\% (w/v) glycerol and the concentration was adjusted to $\approx 300 \mu \mathrm{M}$. Upon mixing with $300 \mathrm{mM}$ of $\mathrm{NaNO}_{2}$, the protein samples were incubated at room temperature for a few minutes. The samples were then quickly transferred into a $3 \mathrm{~mm}$ quartz tube and then rapidly frozen in liquid $\mathrm{N}_{2}$ where they were kept until measurement. Continuous wave (cw)-EPR spectra were recorded on a Bruker ESP-380E spectrometer at $\mathrm{X}$-band frequency equipped with a gas-flow cryogenic system using a liquid He cryostat from Oxford Inc. (ESR 935) and an ITC4 temperature controller. Spectra were recorded at $10 \mathrm{~K}$ with a microwave power of $1 \mathrm{~mW}$, a field modulation of $100 \mathrm{kHz}$, and a modulation amplitude of $0.5 \mathrm{mT}$. The obtained EPR spectra were simulated with the program GEESTRAIN5 V 1.0. ${ }^{73}$

\section{X-ray crystallography}

Protein crystals were obtained from $10 \mathrm{mg} \mathrm{mL}^{-1}$ of NP4(D30N) in water using the vapor-diffusion method upon mixing with an equal volume of $2.8 \mathrm{M}$ ammonium phosphate ( $\mathrm{pH}$ 7.4). The crystals were soaked for $10 \mathrm{~min}$ on ice in $3.2 \mathrm{M}$ potassium phosphate $(\mathrm{pH} 7.4)$ containing $0.3 \mathrm{M} \mathrm{KNO}_{2}$ and afterwards in $3.2 \mathrm{M}$ potassium phosphate ( $\mathrm{pH} 7.4$ ), 15\% glycerol as a cryo protectant. Afterwards, the crystals were immediately frozen in liquid $\mathrm{N}_{2}$ and kept there until the measurement. A diffraction data set was collected at $100 \mathrm{~K}$ using the beamline BL14.2 at BESSYII (Berlin, Germany). The data set was processed with $\mathrm{XDS}^{74}$ and CCP4. ${ }^{75}$ The molecular-replacement method was applied using MOLREP ${ }^{76}$ and an initial model from NP4 (PDB code $3 \mathrm{MVF}) .{ }^{27}$ Model building and refinement were carried out using WINCOOT ${ }^{77}$ and PHENIX, ${ }^{78}$ respectively. The bond/angle parameters of the ligands on iron were refined with restrain. Data collection and refinement statistics are summarized in Table S2. $\dagger$ The stereochemical properties were checked by RAMPAGE. ${ }^{79}$

\section{Acknowledgements}

The authors want to thank Prof. F. Ann Walker, Department of Chemistry and Biochemistry, University of Arizona, Tucson (AZ) for the expression plasmids for the wt proteins of NP1, 2, 4, and 7. The support of Dr Markus Knipp at the initial stage of this study and the technical assistance of Johanna J. Taing and Norbert Dickmann are gratefully acknowledged. The X-ray diffraction was conducted at the beamline BL 14.2 at BESSY II (Helmholtz-Zentrum Berlin, Germany). This work was financially supported by the Max Planck Society and the DFG cluster of excellence RESOLV (EXC 1069).

\section{Notes and references}

1 L. B. Maia and J. J. G. Moura, Chem. Rev., 2014, 114, 5273.

2 B. A. Averill, Chem. Rev., 1996, 96, 2951.

3 C. W. J. Lockwood, T. A. Clarke, J. N. Butt, A. M. Hemmings and D. J. Richardson, Biochem. Soc. Trans., 2011, 39, 1871.

4 S. Nakano, M. Takahashi, A. Sakamoto, H. Morikawa and K. Katayanagi, Chem. Biodiversity, 2012, 9, 1989.

5 P. A. Williams, V. Fülöp, E. F. Garman, N. F. W. Saunders, S. J. Ferguson and J. Hajdu, Nature, 1997, 389, 406.

6 J. O. Lundberg, E. Weitzberg and M. T. Gladwin, Nat. Rev. Drug Discovery, 2008, 7, 156.

7 M. T. Gladwin, A. N. Schechter, D. B. Kim-Shapiro, R. P. Patel, N. Hogg, S. Shiva, R. O. Cannon III, M. Kelm, D. A. Wink, M. G. Espey, E. H. Oldfield, R. M. Pluta, B. A. Freeman, J. R. Lancaster Jr, M. Feelisch and J. O. Lundberg, Nat. Chem. Biol., 2005, 1, 308.

8 M. T. Gladwin, R. Grubina and M. P. Doyle, Acc. Chem. Res., 2009, 42, 157.

9 S. Basu, R. Grubina, J. Huang, J. Conradie, Z. Huang, A. Jeffers, A. Jiang, X. He, I. Azarov, R. Seibert, A. Mehta, R. Patel, B. S. King, N. Hogg, A. Ghosh, M. T. Gladwin and D. B. Kim-Shapiro, Nat. Chem. Biol., 2007, 3, 785.

10 K. H. Hopmann, B. Cardey, M. T. Gladwin, D. B. Kim-Shapiro and A. Ghosh, Chem.-Eur. J., 2011, 17, 6348.

11 F. A. Walker, J. Inorg. Biochem., 2005, 99, 216.

12 M. Knipp and C. He, IUBMB Life, 2011, 63, 304.

13 M. Knipp, H. Zhang, R. E. Berry and F. A. Walker, Protein Expression Purif., 2007, 54, 183. 
14 M. Knipp, H. Ogata, G. Soavi, G. Cerullo, A. Allegri, S. Abbruzzetti, S. Bruno, C. Viappiani, A. Bidon-Chanal and F. J. Luque, F1000Research, 2015, 4, 45.

15 C. He and M. Knipp, J. Am. Chem. Soc., 2009, 131, 12042.

16 J. H. Enemark and R. D. Feltham, Coord. Chem. Rev., 1974, 13, 339.

17 BRENDA enzyme database at, http:/www.brendaenzymes.de/enzyme.php?ecno=1.7.6.1, accessed, March 2016.

18 G. R. A. Wyllie and W. R. Scheidt, Chem. Rev., 2002, 102, 1067.

19 N. Xu, J. Yi and G. B. Richter-Addo, Inorg. Chem., 2010, 49, 6253.

20 O. Einsle, A. Messerschmidt, R. Huber, P. M. H. Kroneck and F. Neese, J. Am. Chem. Soc., 2002, 124, 11737.

21 K. M. Polyakov, K. M. Boyko, T. V. Tikhonova, A. Slutsky, A. N. Antipov, R. A. Zvyagilskaya, A. N. Popov, G. P. Bourenkov, V. S. Lamzin and V. O. Popov, J. Mol. Biol., 2009, 389, 846.

22 B. R. Crane, L. M. Siegel and E. D. Getzoff, Biochemistry, 1997, 36, 12120.

23 J. Yi, M. K. Safo and G. B. Richter-Addo, Biochemistry, 2008, 47, 8247.

24 D. N. Copeland, A. S. Soares, A. H. West and G. B. RichterAddo, J. Inorg. Biochem., 2006, 100, 1413.

25 J. Yi, J. Heinecke, H. Tan, P. C. Ford and G. B. Richter-Addo, J. Am. Chem. Soc., 2009, 131, 18119.

26 B. R. Goblirsch, B. R. Streit, J. L. DuBois and C. M. Wilmot, J. Biol. Inorg. Chem., 2010, 15, 879.

27 C. He, H. Ogata and M. Knipp, Biochemistry, 2010, 49, 5841.

28 C. He, M. Fuchs, H. Ogata and M. Knipp, Angew. Chem., Int. Ed., 2012, 51, 4470.

29 C. He, H. Ogata and M. Knipp, Chem. Biodiversity, 2012, 9, 1761.

30 L. J. Young and L. M. Siegel, Biochemistry, 1988, 27, 2790.

31 B. I. Goetz, H. W. Shields, S. Basu, P. Wang, S. B. King, N. Hogg, M. T. Gladwin and D. B. Kim-Shapiro, Nitric Oxide, 2010, 22, 149.

32 R. Silaghi-Dumitrescu, D. A. Svistunenko, D. Cioloboc, C. Bischin, F. Scurtu and C. E. Cooper, Nitric Oxide, 2014, 42, 32.

33 F. A. Walker, Coord. Chem. Rev., 1999, 185-186, 471.

34 F. A. Walker, Chem. Rev., 2004, 104, 589.

35 M. Fahnenschmidt, R. Bittl, H. K. Rau, W. Haehnel and W. Lubitz, Chem. Phys. Lett., 2000, 323, 329.

36 M. Fahnenschmidt, R. Bittl, E. Schlodder, W. Haehnel and W. Lubitz, Phys. Chem. Chem. Phys., 2001, 3, 4082.

37 G. Zoppellaro, E. Harbitz, R. Kaur, A. A. Ensign, K. L. Bren and K. K. Andersson, J. Am. Chem. Soc., 2008, 130, 15348.

38 G. Zoppellaro, K. L. Bren, A. A. Ensign, E. Herbitz, R. Kaur, H.-P. Hersleth, U. Ryde, L. Hederstedt and R. K. Andersson, Biopolymers, 2009, 91, 1064.

39 S. Van Doorslaer, L. Tilleman, B. Verrept, F. Desmet, S. Maurelli, F. Trandafir, L. Moens and S. Dewilde, Inorg. Chem., 2012, 51, 8834.
40 M. Can, J. Krucinska, G. Zoppellaro, N. H. Andersen, J. E. Wedekind, H.-P. Hersleth, K. K. Andersson and K. L. Bren, ChemBioChem, 2013, 14, 1828.

41 M. Can, G. Zoppellaro, K. K. Andersson and K. L. Bren, Inorg. Chem., 2011, 50, 12018.

42 O. V. Dolomanov, L. J. Bourhis, R. J. Gildea, J. A. K. Howard and H. Puschmann, J. Appl. Crystallogr., 2009, 42, 339.

43 P. Rydberg, E. Sigfridsson and U. Ryde, J. Biol. Inorg. Chem., 2004, 9, 203.

44 R. Singh, R. E. Berry, F. Yang, H. Zhang, F. A. Walker and A. Ivancich, Biochemistry, 2010, 49, 8857.

45 B. C. Finzel, T. L. Poulos and J. Kraut, J. Biol. Chem., 1984, 259, 13027.

46 D. B. Goodin and D. E. McRee, Biochemistry, 1993, 32, 3313. 47 J. Dawson, Science, 1988, 240, 433.

48 T. L. Poulos and J. Kraut, J. Biol. Chem., 1980, 255, 8199.

49 T. L. Poulos, J. Biol. Inorg. Chem., 1996, 1, 356.

50 T. L. Poulos, Chem. Rev., 2014, 114, 3919.

51 P. Vidossich, G. Fiorin, M. Alfonso-Prieto, E. Derat, S. Shaik and C. Rovira, J. Phys. Chem. B, 2010, 114, 5161.

52 M. K. Safo, F. A. Walker, A. M. Raitsimring, W. P. Walters, D. P. Dolata, P. G. Debrunner and W. R. Scheidt, J. Am. Chem. Soc., 1994, 116, 7760.

53 F. A. Walker, H. Nasri, I. Turowska-Tyrk, K. Mohanrao, C. T. Watson, N. V. Shokhirev, P. G. Debrunner and W. R. Scheidt, J. Am. Chem. Soc., 1996, 118, 12109.

54 L. A. Yatsunyk and F. A. Walker, Inorg. Chem., 2004, 43, 4341. 55 T. K. Shokhireva, M. N. Shokhirev, R. E. Berry, H. Zhang and F. A. Walker, J. Biol. Inorg. Chem., 2008, 13, 941.

56 T. K. Shokhireva, A. Weichsel, K. M. Smith, R. E. Berry, N. V. Shokhirev, C. A. Balfour, H. Zhang, W. R. Montfort and F. A. Walker, Inorg. Chem., 2007, 46, 2041.

57 M. Rivera, G. A. Caignan, A. V. Astashkin, A. M. Raitsimring, T. K. Shokhireva and F. A. Walker, J. Am. Chem. Soc., 2002, 124, 6077.

58 S.-i. J. Takayama, G. Ukpabi, M. E. P. Murphey and A. G. Mauk, Proc. Natl. Acad. Sci. U. S. A., 2011, 108, 13071.

59 J. Conradie and A. Ghosh, Inorg. Chem., 2006, 45, 4902.

60 M. D. Liptak, X. Wen and K. L. Bren, J. Am. Chem. Soc., 2010, 132, 9753.

61 J. G. Kleingardner, S. E. J. Bowman and K. L. Bren, Inorg. Chem., 2013, 52, 12933.

62 T. K. Shokhireva, R. E. Berry, E. Uno, C. A. Balfour, H. Zhang and F. A. Walker, Proc. Natl. Acad. Sci. U. S. A., 2003, 100, 3778.

63 C. He, B. D. Howes, G. Smulevich, S. Rumpel, E. J. Reijerse, W. Lubitz, N. Cox and M. Knipp, J. Am. Chem. Soc., 2015, 137, 4141.

64 J. T. Landrum, K. Hatano, W. R. Scheidt and C. A. Reed, J. Am. Chem. Soc., 1980, 102, 6729.

65 S. E. J. Bowman and K. L. Bren, Inorg. Chem., 2010, 49, 7890. 66 M. Ayala, in Biocatalysis Based on Heme Peroxidases, ed. E. Torres and M. Ayala, Springer Berlin Heidelberg, 2010, vol. 4, p. 61.

67 W. Jentzen, J. G. Ma and J. A. Shelnutt, Biophys. J., 1998, 74, 753. 
68 J. F. Andersen, X. D. Ding, C. Balfour, T. K. Shokhireva, D. E. Champagne, F. A. Walker and W. R. Montfort, Biochemistry, 2000, 39, 10118.

69 X. D. Ding, A. Weichsel, J. F. Andersen, T. K. Shokhireva, C. Balfour, A. J. Pierik, B. A. Averill, W. R. Montfort and F. A. Walker, J. Am. Chem. Soc., 1999, 121, 128.

70 http://www.electrochem.org/dl/ma/206/pdfs/0108.pdf, accessed, March 2016.

71 S. J. Strickler and M. Kasha, J. Am. Chem. Soc., 1963, 85, 2899.

72 R. E. Berry, T. K. Shokhireva, I. Filippov, M. N. Shokhirev, H. Zhang and F. A. Walker, Biochemistry, 2007, 46, 6830.

73 W. R. Hagen, Biomolecular EPR Spectroscopy, CRC Press, Boca Raton, Florida, USA, 2009.

74 W. Kabsch, J. Appl. Crystallogr., 1993, 26, 795.

75 M. D. Winn, C. C. Ballard, K. D. Cowtan, E. J. Dodson, P. Emsley, P. R. Evans, R. M. Keegan, E. B. Krissinel, A. G. W. Leslie, A. McCoy, S. J. McNicholas,
G. N. Murshudov, N. S. Pannu, E. A. Potterton, H. R. Powell, R. J. Read, A. Vagin and K. S. Wilson, Acta Crystallogr., Sect. D: Biol. Crystallogr., 2011, 67, 235.

76 A. Vagin and A. Teplyakov, J. Appl. Crystallogr., 1997, 30, 1022.

77 P. Emsley and K. Cowtan, Acta Crystallogr., Sect. D: Biol. Crystallogr., 2004, 60, 2126.

78 P. D. Adams, P. V. Afonine, G. Bunkoczi, V. B. Chen, I. W. Davis, N. Echols, J. J. Headd, L. W. Hung, G. J. Kapral, R. W. Grosse-Kunstleve, A. J. McCoy, N. W. Moriarty, R. Oeffner, R. J. Read, D. C. Richardson, J. S. Richardson, T. C. Terwilliger and P. H. Zwart, Acta Crystallogr., Sect. D: Biol. Crystallogr., 2010, 66, 213.

79 S. C. Lovell, I. W. Davis, W. B. Arendall III, P. I. W. de Bakker, J. M. Word, M. G. Prisant, J. S. Richardson and D. C. Richardson, Proteins: Struct., Funct., Genet., 2003, 50, 437. 